\title{
Effects of freeze-thaw cycles on anaerobic microbial processes in an Arctic intertidal mud flat
}

\author{
Joanna E Sawicka ${ }^{1}$, Alberto Robador ${ }^{1,5}$, Casey Hubert ${ }^{1,4}$, Bo Barker Jørgensen ${ }^{1,2}$ and \\ Volker Brüchert ${ }^{1,3}$ \\ ${ }^{1}$ Department of Biogeochemistry, Max Planck Institute for Marine Microbiology, Bremen, Germany; \\ ${ }^{2}$ Department of Biological Sciences-Microbiology Section, Center for Geomicrobiology, Department of \\ Biological Sciences, Aarhus University Ny Munkegade, Aarhus C, Denmark and ${ }^{3}$ Department of Geology and \\ Geochemistry, Stockholm University, Stockholm, Sweden
}

\begin{abstract}
Insight into the effects of repeated freezing and thawing on microbial processes in sediments and soils is important for understanding sediment carbon cycling at high latitudes acutely affected by global warming. Microbial responses to repeated freeze-thaw conditions were studied in three complementary experiments using arctic sediment collected from an intertidal flat that is exposed to seasonal freeze-thaw conditions (Ymerbukta, Svalbard, Arctic Ocean). The sediment was subjected to oscillating freeze-thaw incubations, either gradual, from -5 to $4{ }^{\circ} \mathrm{C}$, or abrupt, from -20 to $10^{\circ} \mathrm{C}$. Concentrations of low-molecular weight carboxylic acids (volatile fatty acids) were measured and sulfate reduction was assessed by measuring ${ }^{35} \mathrm{~S}$ sulfate reduction rates (SRRs). Gradual freezethaw incubation decreased microbial activity in the frozen state to $0.25 \%$ of initial levels at $4{ }^{\circ} \mathrm{C}$, but activity resumed rapidly reaching $>60 \%$ of initial activity in the thawed state. Exposure of sediments to successive large temperature changes $(-20$ versus $10 \mathrm{C}$ ) decreased SRR by $80 \%$ of the initial activity, suggesting that a fraction of the bacterial community recovered rapidly from extreme temperature fluctuations. This is supported by 16S rRNA gene-based denaturing gradient gel electrophoresis profiles that revealed persistence of the dominant microbial taxa under repeated freeze-thaw cycles. The fast recovery of the SRRs suggests that carbon mineralization in thawing arctic sediment can resume without delay or substantial growth of microbial populations.

The ISME Journal (2010) 4, 585-594; doi:10.1038/ismej.2009.140; published online 24 December 2009

Subject Category: microbial ecosystem impacts

Keywords: arctic sediment; freeze-thaw effects; sulfate reduction; fermentation; volatile fatty acids; DGGE
\end{abstract}

\section{Introduction}

Annual freezing and thawing are common features of high-latitude sediments and soils. Arctic marine coastal environments, such as intertidal mud flats, are exposed to freeze-thaw events in spring and in fall. Shallow-water shelf sediments cover more than $50 \%$ of the Arctic Ocean (Jakobsson et al., 2002)—a region sensitive to temperature increases due to climate change. It has been predicted that the warming of arctic environments will thaw terrestrial and drowned submarine permafrost, which may lead to substantial activation of resident microbiota (Schuur et al., 2009). Studies on freeze-thaw cycling

Correspondence: JE Sawicka, Department of Biogeochemistry, Max Planck Institute for Marine Microbiology, Celsiusstr 1, Bremen, 28359, Germany.

E-mail: jsawicka@mpi-bremen.de

${ }^{4}$ Present address: School of Civil Engineering and Geosciences, Newcastle University, Newcastle upon Tyne, NE1 7RU, United Kingdom

${ }^{5}$ Present address: Department of Oceanography, University of Hawaii NASA Astrobiology Institute, 213 Physical Science Building, 2565 McCarthy Mall, Honolulu, HI 96822, USA

Received 9 November 2009; accepted 22 November 2009; published online 24 December 2009 and its effects on marine microbial processes have not been conducted for coastal marine sediments. The Svalbard archipelago contains intertidal sediments that freeze periodically at the turn of seasons. Sediments from this archipelago have been the subject of extensive microbial ecology and biogeochemical studies on temperature adaptation (for example, Arnosti et al., 1998; Sagemann et al., 1998; Ravenschlag et al., 2000; Finke and Jørgensen, 2008); however, the effect of freeze-thaw cycles on microbial communities in this environment is unknown.

Freeze-thaw events affect the activity and population dynamics of microorganisms in sediments and soils because strong fluctuations in temperature can damage or destroy microbial cells and disrupt cell aggregates (for example, Schimel and Clein, 1996; Eriksson et al., 2001; Sharma et al., 2006; Mountfort et al., 2003; Schimel and Mikan, 2005; Walker et al., 2006; Yergeau and Kowalchuk, 2008; Männistö et al., 2009). This phenomenon has been studied in soils, in which freezing elevates the salinity while lowering water and nutrient availability (Eriksson et al., 2001; Sharma et al., 2006; Yergeau and Kowalchuk, 2008). Nutrients that are released from aggregates during thawing become 
available to microorganisms that survive freezing, resulting in temporary stimulation of microbial activity that had been low or negligible in the frozen state (Schimel and Clein, 1996; Pesaro et al., 2003; Grogan et al., 2004). Sharma et al. (2006) showed that at the turn of winter to spring, freeze-thaw cycles enhanced denitrification and caused a surge in $\mathrm{N}_{2} \mathrm{O}$ and $\mathrm{CO}_{2}$ emissions from soil. However, experiments designed to simulate the effect of intermittent warm Chinook winds in western Canadian soils indicated that repeated freeze-thaw cycles substantially decreased the viability of microorganisms (Walker et al., 2006). Statistical analysis of DNA- and RNA-based molecular fingerprinting of Antarctic soil microbial community also showed that frequent freeze-thaw cycles decreased the abundance of $16 \mathrm{~S}$ rRNA genes and changed the microbial community diversity (Yergeau and Kowalchuk, 2008).

The purpose of this study was to subject natural communities of marine bacteria in seasonally freezing arctic sediment to different freeze-thaw treatments and to examine the effect on anaerobic carbon mineralization processes. Incubation experiments were conducted using sediment from an intertidal flat in the Svalbard archipelago to measure microbial sulfate reduction rates (SRRs) and concentrations of volatile fatty acids (VFAs). Different temperature regimes and freeze-thaw gradients were applied to simulate different scenarios experienced by this sediment annually.

\section{Materials and methods}

Sampling site

Sediment was collected from Ymerbukta, an intertidal flat in a shallow embayment in Isfjorden $\left(78^{\circ} 16^{\prime} 61 \mathrm{~N}, 014^{\circ} 02^{\prime} 69 \mathrm{E}\right)$ on the west coast of the Svalbard archipelago. This site freezes in the fall when the air temperature in Isfjorden drops to as low as $-20^{\circ} \mathrm{C}$, and thaws in the following summer, when it reaches temperatures as high as $9{ }^{\circ} \mathrm{C}$ (Nordli, 2005). Samples were collected in August 2006 and August 2007. The temperature of the sediment at the time of samplings was $6.5^{\circ} \mathrm{C}$ and the air temperature was $6.5^{\circ} \mathrm{C}$. For in situ measurements, 26-mm diameter sediment cores penetrating to $16 \mathrm{~cm}$ depth were sealed at both ends with rubber stoppers, leaving air in the headspace, and stored at $4{ }^{\circ} \mathrm{C}$. For sediment and slurry incubation experiments, samples were collected at low tide from the zone of highest sulfate reduction $(3-9 \mathrm{~cm}$ depth; Figure 1a). Sediment was stored in gas-tight polyethylene bags at $4{ }^{\circ} \mathrm{C}$ until further processing in the laboratory.

\section{Freeze-thaw experiments}

To simulate freeze-thaw cycles, sediment was subjected to three different time course experiments with different temperature amplitudes and time periods.
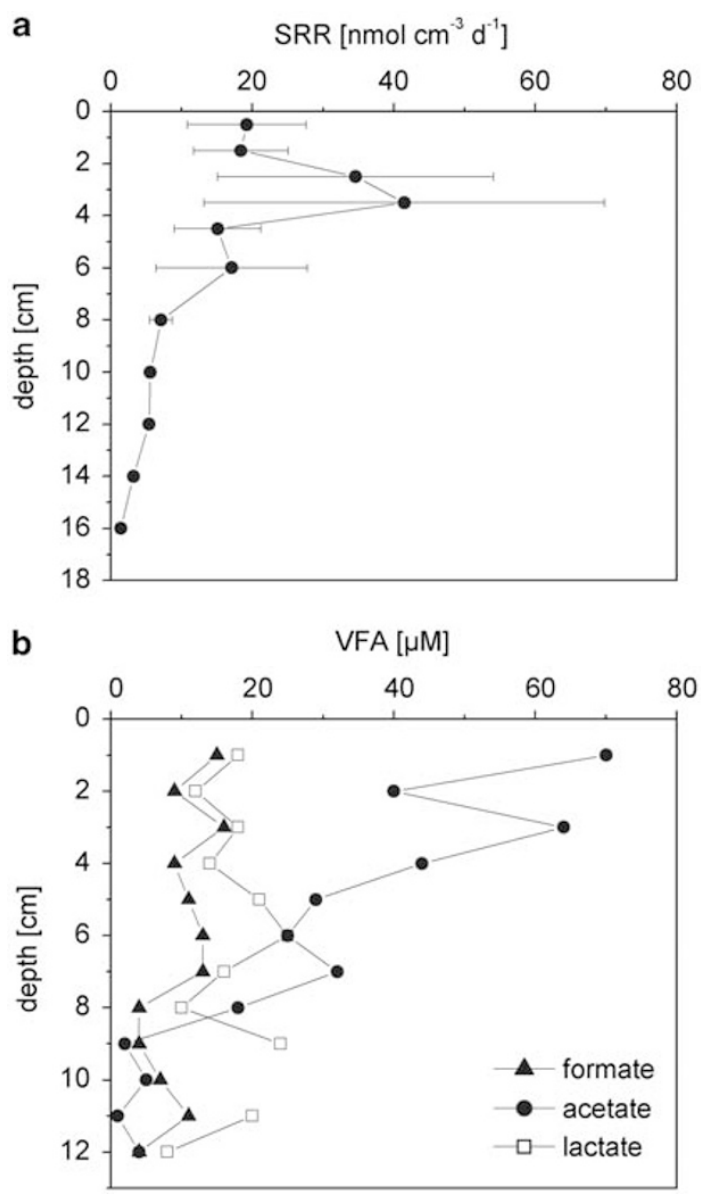

Figure 1 (a) Depth profile of sulfate reduction rates (SRRs) in Ymerbukta sediment. The SRR values were determined at $7{ }^{\circ} \mathrm{C}$, error bars correspond to SRR values measured in duplicate cores. (b) Concentrations of volatile fatty acids (VFAs) in Ymerbukta sediment.

\section{Gradual freeze-thaw incubation}

The purpose of this experiment was to simulate a natural freeze-thaw process in the sediments. At the turn of seasons, sediments are likely to experience freeze-thaw event that happens over 24-h cycles. A total of $150 \mathrm{~g}$ of sediment was mixed with anoxic seawater medium (Widdel and Hansen, 1991) in a weight ratio of 1:2. The slurry was distributed under $\mathrm{N}_{2}$ into 15-ml Hungate tubes (3 ml) (Ochs $\mathrm{GmBH}$, Bovenden/Lenglern, Germany) and 200-ml Duran culture bottles $(100 \mathrm{ml})$ (DURAN Group $\mathrm{GmbH}$, Wertheim/Main, Germany) and sealed with butyl rubber stoppers. To simulate slow freezing and subsequent thawing conditions, sediment slurries were subjected to stepwise temperature changes over 20 days. The incubation temperature was consecutively lowered in 24-h intervals from 4 to $2,0,-2$ and $-5{ }^{\circ} \mathrm{C}$, and was subsequently increased from -5 to 0 , 2 and $4{ }^{\circ} \mathrm{C}$ in the thawing phase. The SRR values were determined for each time interval.

The Hungate tubes and culture bottles were incubated in a temperature-regulated water bath filled with dilute antifreeze liquid for convenient 
temperature manipulation. To determine the SRR value, $20 \mu \mathrm{l}$ of ${ }^{35} \mathrm{~S}$-sulfate tracer $(100 \mathrm{kBq})$ was injected into triplicate Hungate tubes that were incubated for $24 \mathrm{~h}$ before the change in temperature. The SRR value, therefore, represents the average rate for a 24-h interval. In addition, VFA concentrations were measured in 4-ml sub-samples removed from the $200-\mathrm{ml}$ culture bottles at the end of each $24-\mathrm{h}$ time interval.

\section{Long-term freeze-thaw incubation}

This experiment mimicked mid-winter to midsummer difference (frozen and thawed, respectively) and explored the scale and rate of recovery of bacteria from frozen state. Undiluted, homogenized sediment was incubated for 12 weeks alternately at $-20^{\circ} \mathrm{C}$ for 3 weeks and at $10{ }^{\circ} \mathrm{C}$ for 3 weeks. Sediment was sub-sampled from the polyethylene bag into $5-\mathrm{ml}$ glass cylinders in a nitrogen-filled Two-hand AtmosBag (Sigma-Aldrich, Steinheim, Germany) to maintain anoxic conditions. The cylinders contained ca. $3 \mathrm{ml}$ sediment and were sealed at both ends with butyl rubber stoppers. Before each sediment extraction, the bag was homogenized for 10 min by manual kneading. After the sub-samples were taken the sediment tubes were kept for a week at $0{ }^{\circ} \mathrm{C}$ before the start of the 12 -week incubation. This period was necessary to allow SRR to decrease again after a temporary stimulation due to sediment mixing-a phenomenon that has been observed previously (Finke and Jørgensen, 2008). After each freeze and thaw period, three tubes were removed to determine sulfate concentration, SRR and the total cell number by 4,6-Diaminodino-2phenylindole (DAPI) staining. All analyses were determined in triplicates. Additional sub-samples were incubated under the same conditions for denaturing gradient gel electrophoresis (DGGE) profiling of the bacterial community. To determine the SRR value in this particular experiment, $5 \mu \mathrm{l}$ of ${ }^{35} \mathrm{~S}$-sulfate tracer containing $500 \mathrm{kBq}$ was injected into sub-samples at the start of the 12-week incubation period. Samples were incubated with tracer for three, six, nine and twelve weeks, respectively. As a control assay, sediment was sterilized by autoclaving for $25 \mathrm{~min}$ at $120^{\circ} \mathrm{C}$ and was then incubated with the same amount of tracer at $10^{\circ} \mathrm{C}$. Four additional control incubation experiments were initiated with sulfate radiotracer added to sediments that were immediately frozen, incubated frozen for 1, 2, 5 and 10 weeks, and thawed only before fixation in zinc acetate. Incubations were terminated by extruding the sediment from glass tubes into centrifuge tubes containing $10 \mathrm{ml}$ of $20 \%(\mathrm{w} / \mathrm{v})$ zinc acetate solution, then homogenizing it with a vortex mixer and freezing it at $-20^{\circ} \mathrm{C}$. As tracer was injected at the beginning of the experiment, total reduced inorganic ${ }^{35}$ sulfide $\left({ }^{35} \mathrm{~S}\right.$-TRIS) represents cumulative sulfide formed during frozen and thawed periods. Threeweek averages of SRR were then calculated as the difference in TRIS activity between the beginning and the end of each experimental period, as exemplified for the first thawed period:

$$
\begin{aligned}
& \mathrm{SRR}=\left[\mathrm{SO}_{4}^{-2}\right] * \rho_{\text {sed }} * \frac{{ }^{35} \mathrm{TRIS}_{\mathrm{c}}-{ }^{35} \mathrm{TRIS}_{\mathrm{b}}}{a_{\text {total }}} * \frac{1}{t} * 1.06 \\
& \quad * 1000
\end{aligned}
$$

where SRR is the SRR; $\mathrm{SO}_{4}^{-2}$ the sulfate concentration in the porewater of the sediment sample; $\rho_{\text {sed }}$ the porosity of the sediment; ${ }^{35}$ TRIS the radioactivity of total reduced inorganic sulfur (counts per minute, c.p.m.); $b$ the first frozen period (first 3 weeks, that is, the incubation time); $c$ the sum of frozen and thawed periods (6 weeks); $a_{\text {total }}$ the total radioactivity used (c.p.m.); and 1.06 is the correction factor for the expected isotopic fractionation;

The number 1000 is the factor for conversion from nmol $\mathrm{l}^{-1}$ to $\mathrm{nmol} \mathrm{cm}{ }^{-3}$.

\section{Multiple freeze-thaw incubations}

The purpose of this experiment was to test the long-term survival of bacteria under repeated freeze-thaw conditions. This experiment consisted of eight freeze-thaw cycles, each of which covered a 12-h frozen phase at $-20^{\circ} \mathrm{C}$ and an 18-h thawed phase at $10^{\circ} \mathrm{C}$. The SRR values were determined at the end of each thawed phase. As a control an additional incubation was carried out at $10^{\circ} \mathrm{C}$ and rates were determined for the same cycle intervals as for the freeze-thaw treatments.

Sediment slurries ( $150 \mathrm{ml}, 1: 2 \mathrm{v} / \mathrm{v})$ were incubated while stirring during the thawed phase. The control slurry was constantly stirred. To measure SRR values, sub-samples of $3 \mathrm{ml}$ were transferred into $\mathrm{N}_{2}$-flushed glass Hungate tubes and sealed with butyl rubber stoppers. A volume of $20 \mu \mathrm{l}$ of ${ }^{35} \mathrm{~S}$ sulfate tracer (activity: $100 \mathrm{kBq}$ ) was injected into triplicate tubes at each time point. The SRR values were measured for the duration of each thawed phase and at the corresponding times in the control slurry. The VFA concentrations were measured by sub-sampling ca. $4 \mathrm{ml}$ of slurry at the end of each thawed phase and at the corresponding time points from the control slurry.

\section{Sulfate reduction rates}

In situ SRR values were measured in two parallel cores using a whole-core incubation method (Jørgensen, 1978) by injecting $5 \mu \mathrm{l}$ of carrier-free, ${ }^{35} \mathrm{SO}_{4}^{2-}$ tracer solution in $4 \% \mathrm{NaCl}(\sim 100 \mathrm{kBq}$ per injection) in 1-cm intervals to a depth of $16 \mathrm{~cm}$. Incubations were carried out for $8 \mathrm{~h}$ at $7^{\circ} \mathrm{C}$. All samples were distilled using the low-blank cold chromium distillation method described in the study by Kallmeyer et al. (2004). Briefly, centrifuged sediment was diluted with $10 \mathrm{ml}$ dimethylformamide 
and placed in a distillation flask. Total reduced inorganic sulfide (TRIS) was acid-distilled under nitrogen at room temperature by adding $12 \mathrm{ml} 6 \mathrm{~N} \mathrm{HCl}$ and $12 \mathrm{ml} 1 \mathrm{M}$ chromium chloride to the solution. The TRIS was recovered as zinc sulfide in traps containing $7 \mathrm{ml}$ of $5 \%$ zinc acetate solution and ${ }^{35} \mathrm{~S}$ was counted in a liquid scintillation counter (Packard, Tricarb 2500 TR, Packard-Becker BV, Groningen, The Netherlands) without luminescence correction and the high sensitivity mode turned off; energy range $4-167 \mathrm{keV}$. The scintillation cocktail used was Lumasafe Plus (Lumac BV, Groningen, The Netherlands) mixed with the ZnS solution in a ratio of $2: 1(\mathrm{v} / \mathrm{v})$.

\section{Volatile fatty acid measurements}

Volatile fatty acids were measured by high-performance liquid chromatography according to the method of Albert and Martens (1997). Measurements of in situ VFA concentrations were carried out on sediment core sliced at the following depths: 0-1, $1-2,2-3,3-4,4-5,5-7,7-9,9-10$ and $11-12 \mathrm{~cm}$. Sediment and slurry sub-samples were centrifuged in Spinex tubes at 4000 r.p.m. at $4{ }^{\circ} \mathrm{C}$ for $15 \mathrm{~min}$ and porewater sub-samples were directly filtered into 1-ml brown borosilicate glass vials (pre-combusted at $480{ }^{\circ} \mathrm{C}$ for $4 \mathrm{~h}$ ) to minimize possible contamination. Acids were derivatized with $p$-nitrophenyl hydrazine, separated by high-performance liquid chromatography using a LiChrosphere 80/100 (Knauer, Berlin, Germany) column at $25^{\circ} \mathrm{C}$, and the concentrations were determined by UV absorption with a UV/VIS detector (Linear) at $400 \mathrm{~nm}$ and quantified with commercially available software (Chromstar, SES GmbHAQ11, Bechenheim, Germany). Concentrations were determined after calibration with standard mixtures containing glycolate, formate, lactate, acetate, propionate, isobutyrate, butyrate and valerate. A standard was measured after every fifth sample. The detection limits for the different acids were $0.2 \mu \mathrm{M}$ for glycolate and lactate, $1 \mu \mathrm{M}$ for acetate and formate (in samples with high acetate concentrations formate occurred as a rider peak on the acetate shoulder; for peak integration, a vertical drop line was used for peak separation, which led to a slight overestimation of the formate peak), $0.5 \mu \mathrm{M}$ for propionate and isobutyrate and $2 \mu \mathrm{M}$ for butyrate, valerate and isovalerate. Only lactate, acetate and formate were detected in our samples; other acids were below the detection limits. The s.d. value for replicate analyses is less then $3 \%$ for concentrations above $5 \mu \mathrm{M}$ (Finke, 2003).

\section{Enumeration of total cells}

Total cell numbers were counted by epifluorescence microscopy after staining with DAPI. Total cell counts were determined in triplicate in the original sediment bag stored at $0{ }^{\circ} \mathrm{C}$ for 1 month (time point 0) after sampling, and in samples taken after each time point for all experiments. For DAPI staining, sediment samples were treated as described previously (Pernthaler et al., 2002). Sediment was sub-sampled $(0.5 \mathrm{ml})$ and fixed in $4 \%$ paraformaldehyde ( 1 part $24 \%$ paraformaldehyde and 5 parts $1 \times$ phosphate-buffered saline, PBS) overnight at $4{ }^{\circ} \mathrm{C}$. Fixed samples were washed three times with $1 \times$ PBS, with centrifugation steps at 10000 r.p.m. for $5 \mathrm{~min}$ between washes, and stored in PBS/ ethanol (2:3) at $-20^{\circ} \mathrm{C}$ until further processing. Samples were then diluted (1:2) in PBS/ethanol and sonicated at minimum power for $20 \mathrm{~s}$ with a sonication probe (MS73 Sonopulus HD70 Bandelin, Berlin, Germany). Sub-samples of $10 \mu \mathrm{l}$ of the suspension were added to $8 \mathrm{ml}$ of PBS, filtered onto polycarbonate membrane filters (Isopore, filter code: GTTP; pore size: $0.2 \mu \mathrm{m}$; diameter: $21 \mathrm{~mm}$, Millipore, Schwalbach/Ts, Germany) and stored at $-20^{\circ} \mathrm{C}$. Before staining, filters were cut into several sections. The stain, DAPI $\left(10 \mu \mathrm{l}\right.$ of a $1-\mu \mathrm{g} \mathrm{ml}^{-1}$ working solution) was dropped onto the filter sections and incubated in the dark for $5 \mathrm{~min}$. Filters were then washed twice in MilliQ water, finally embedded in Vectashield mixed with Citifluor AF1 antifadent (Plano, Wetzlar, Germany) and covered with a cover slip. For each replicate, at least 1000 DAPI-stained cells were counted. Bacterial counts were converted into cells per $\mathrm{ml}$ of sediment.

\section{DNA extraction and PCR amplification}

The extraction of DNA from the sediment was done using the Mo Bio Power Soil Kit (Mo Bio Laboratories, Inc., CA, USA). Amplification of 16S rRNA genes was performed as described by Muyzer et al. (1997) using the universal primers: 907r (5'-CCGTCAATT CCTTTRAGTTT- $\left.3^{\prime}\right)$ and 352f (5'-CCTACGGGAGGCA GCAG-3') carrying a GC clamp (Muyzer et al., 1997). A PCR protocol was used as described by Muyzer et al. (1997) except that 'touchdown' PCR was used to increase the specificity of the amplification and to reduce the formation of by-products, that is, the annealing temperature was set $10^{\circ} \mathrm{C}$ above the expected annealing temperature and decreased by $1^{\circ} \mathrm{C}$ every two cycles until an annealing temperature of $55{ }^{\circ} \mathrm{C}$ was reached at which nine additional cycles were performed. The program started with a hot start at $94{ }^{\circ} \mathrm{C}$ for $5 \mathrm{~min}$ (20 cycles in total; Muyzer et al., 1997).

\section{Denaturing gradient gel electrophoresis}

Denaturing gradient gel electrophoresis was performed using a Bio-Rad D Code system (Bio-Rad, Munich, Germany). Polyacrylamide gel was poured with a gradient pump (Econo Gradient Pump, BioRad) to achieve gradient ranging from $0 \%$ to $80 \%$ acrylamide. The gel was polymerized by adding $10 \%$ ammonium persulfate and $N, N, N^{\prime}, N^{\prime}$-tetramethylethylenediamine (Bio-Rad, Munich, Germany) before pouring the gel. A volume of $80 \mu \mathrm{l}$ of each PCR product was applied onto the gel and the DGGE was 
then performed at $60^{\circ} \mathrm{C}$ and a constant voltage of $200 \mathrm{~V}$ for $3.5 \mathrm{~h}$ (Nübel et al., 1999). After electrophoresis, the gel was incubated for $30 \mathrm{~min}$ in an aqueous ethidium bromide solution $\left(0.5 \mu \mathrm{g} \mathrm{l}^{-1}\right)$ and visualized on a UV transilluminator (LTF-Labortechnik, Wasserburg, Germany).

\section{Results}

Characterization of study site

The sediments were gray bioturbated muds with water content of $40 \%$, an average total organic carbon concentration of $1,5 \%$ dry weight and a $\mathrm{C} / \mathrm{N}$ ratio of 16. The SRR value increased from $19 \mathrm{nmol} \mathrm{cm}^{-3} \mathrm{day}^{-1}$ at the sediment surface to $41 \mathrm{nmol} \mathrm{cm}^{-3}$ day $^{-1}$ at $3 \mathrm{~cm}$ depth and decreased below this depth (Figure 1a). At the study site, only three VFAs were detected: acetate, lactate and formate (Figure 1b). The acetate concentration was highest in the surface centimeter, and decreased from 70 to $4 \mu \mathrm{M}$ at $12 \mathrm{~cm}$ depth. The range of lactate and formate concentrations was 8-25 and $4-16 \mu \mathrm{M}$, respectively, and did not show clear trends with depth.

\section{Gradual freeze-thaw incubation}

The SRR values are presented for the gradual freezethaw incubations in Figure 2a. At the beginning of the experiment at $+4{ }^{\circ} \mathrm{C}$, the SRR value was $12 \mathrm{nmol} \mathrm{cm}^{-3}$ day $^{-1}$, which was the highest rate measured in this experiment. Over the next 5 days of stepwise lowered incubation temperature (2, 0 , -2 and $-5{ }^{\circ} \mathrm{C}$ ), SRR dropped to $7.5,5.0,2.1$ and $0.4 \mathrm{nmol} \mathrm{cm}^{-3}$ day $^{-1}$, respectively. The subsequent increase in temperature to $0^{\circ} \mathrm{C}$ (that is, the 24 -h thawing period) resulted in SRR increasing 20-fold to $7.0 \mathrm{nmol} \mathrm{cm}^{-3} \mathrm{day}^{-1}$. During the second temperature cycle $\left(2,4,2,0\right.$ and $\left.-2{ }^{\circ} \mathrm{C}\right)$, SRR values were in the range of $2.9-7.8 \mathrm{nmol} \mathrm{cm}^{-3}$ day $^{-1}$ and did not show any of the trends as observed during the first cycle. Sulfate reduction was not detected during the second freezing interval but resumed at $6.0 \mathrm{nmol} \mathrm{cm}^{-3}$ day $^{-1}$ during the $0{ }^{\circ} \mathrm{C}$ thawing phase. The third temperature cycle resulted in SRR patterns that were similar to those observed during the second cycle.

The VFA concentrations versus time are presented in Figure 2b. Only acetate and lactate were detected during the gradual freeze-thaw incubation. As there was no significant trend for the individual VFAs, their peak areas were summed together. The sum analytical error is therefore about $6 \%$. At the beginning of the experiment, the sum VFA was $21 \mu \mathrm{M}$. The concentrations of VFA decreased as the sediment was cooled down and remained between 4 and $10 \mu \mathrm{M}$ throughout the remainder of the experiment. The observed fluctuations after the initial temperature decrease were within the range of uncertainty of the method and were insensitive to changes in temperature.
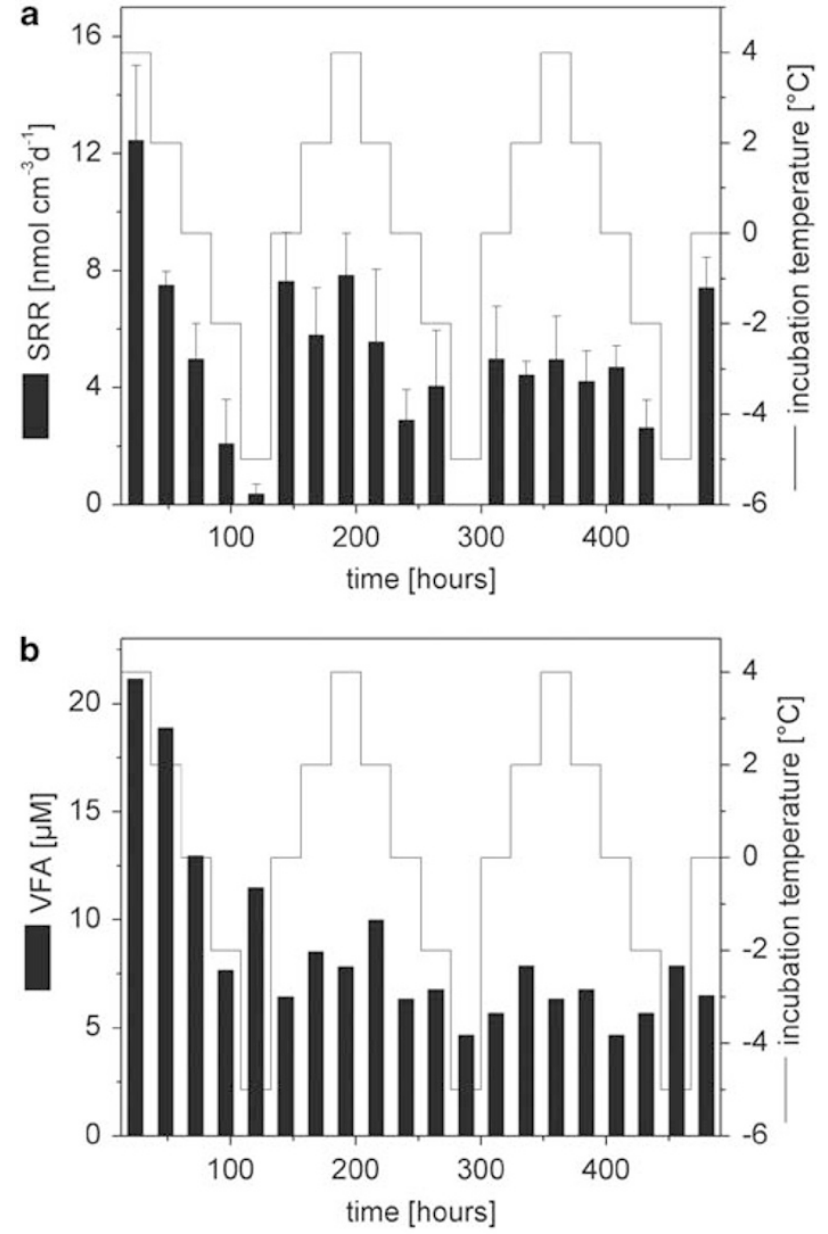

Figure 2 (a) The sulfate reduction rates (SRRs) during the gradual freeze-thaw experiment. The black line corresponds to different temperatures applied during the experiment. Black bars correspond to SRRs measured every $24 \mathrm{~h}$, at respective temperatures. (b) Concentrations of volatile fatty acids (VFAs) determined in the gradual freeze-thaw experiment. The analytical error for the summed VFA concentration is about $6 \%$, as described in the text. The black line corresponds to different temperatures applied during the experiment. Black bars correspond to VFA levels measured every $24 \mathrm{~h}$, at respective temperatures.

\section{Long-term freeze-thaw incubation}

The SRR results for the long-term experiment are presented in Figure 3A. The ${ }^{35} \mathrm{~S}$-TRIS counts after 3 weeks of incubation at $-20^{\circ} \mathrm{C}$ were above background level for ${ }^{35} \mathrm{~S}$-TRIS of the sterilized control assay and the mean rate determined for this 3-week period was $0.06 \mathrm{nmol} \mathrm{cm}^{-3}$ day $^{-1}$ (Figure 3A). This very low SRR value probably is due to the time it took the sediment to cool down from $4{ }^{\circ} \mathrm{C}$ and freeze. This is supported by a ten-week long, control incubation experiment at $-20{ }^{\circ} \mathrm{C}$. The ${ }^{35} \mathrm{~S}$-TRIS counts measured in sediments incubated at $-20^{\circ} \mathrm{C}$ for ten weeks were at the same level as ${ }^{35} \mathrm{~S}$-TRIS counts determined for the 3-week long incubation. In the subsequent 3 -week period at $10^{\circ} \mathrm{C}$, average SRR increased to $38 \mathrm{nmol} \mathrm{cm}^{-3}$ day $^{-1}$, which was higher than the earlier in-situ microbial activity, 

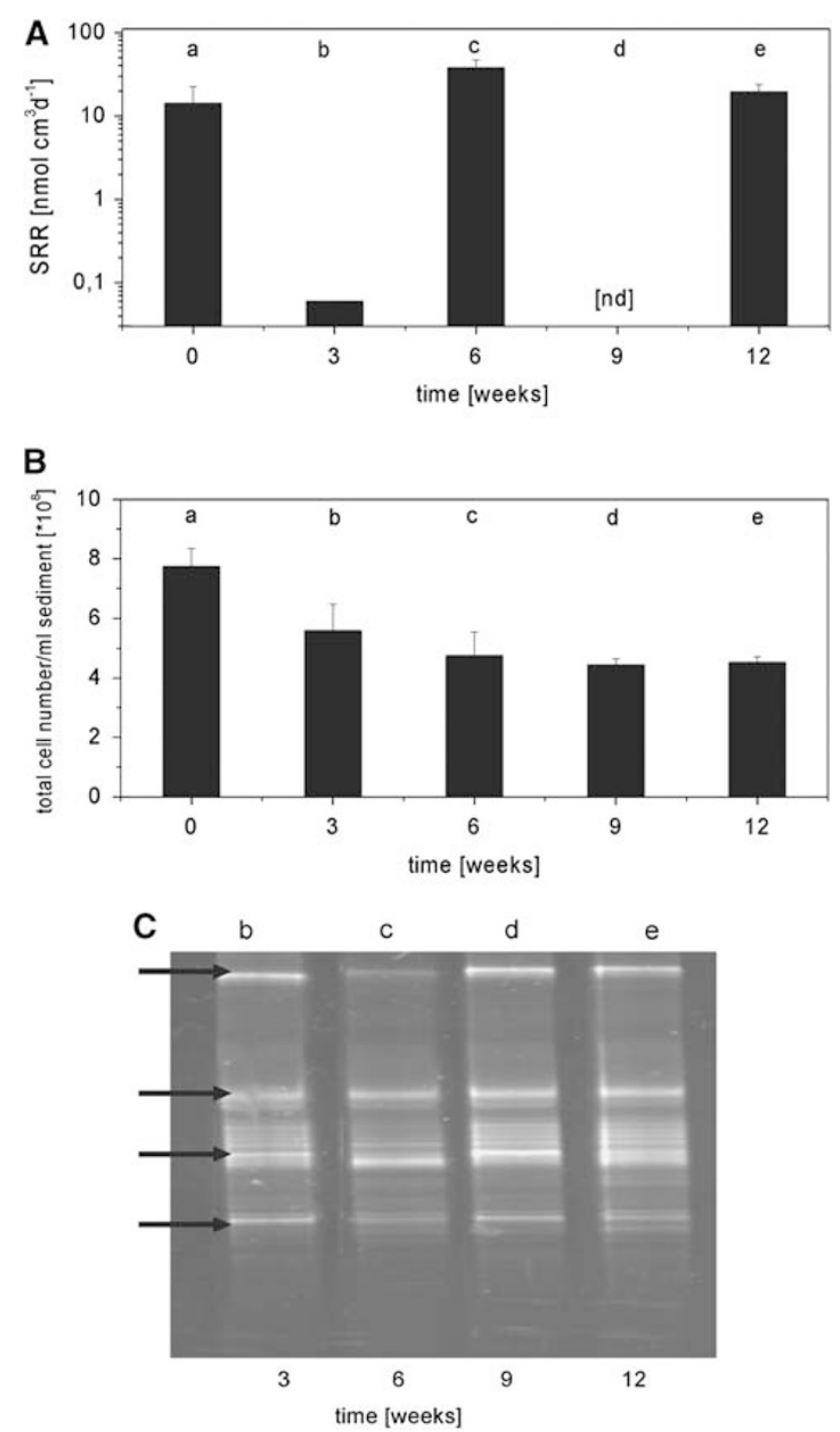

Figure 3 (A) The sulfate reduction rates (SRRs) determined at in situ temperature (a) followed by alternating freezing (b and d) and thawing (c and e) conditions. During the second frozen phase (weeks 6 to 9) sulfate reduction was not detected (nd). (B) Total cell numbers determined for the sediment stored at $0{ }^{\circ} \mathrm{C}$ (a) and for the sediment subjected to alternating freezing (b and d) and thawing (c and e) conditions. (C) Denaturing gradient gel electrophoresis (DGGE) profiles for 16S rRNA gene fragments obtained from DNA extracted after alternating freezing (b and d) and thawing (c and e) conditions, which was amplified by PCR using primers 338f and 907r. The arrows indicate four dominant bands that were prominent in all samples.

suggesting survival of, at least part of, the sulfatereducing community during the $-20^{\circ} \mathrm{C}$ period, and its subsequent reactivation at $10^{\circ} \mathrm{C}$. After the second 3 -week freezing period (that is, at week 9 of the experiment), measured ${ }^{35} \mathrm{~S}$-TRIS counts in triplicate tubes were not significantly higher than the ${ }^{35} \mathrm{~S}$-TRIS counts measured at the beginning of the freeze period (that is, at week 6). Thus, because of the high ${ }^{35} \mathrm{~S}$-TRIS background, SRR values could not be determined for the second freeze period. After the second 3-week period at $+10^{\circ} \mathrm{C}$ (that is, at week 12), ${ }^{35} \mathrm{~S}$-TRIS counts had increased further. The mean rate for this second thaw period was $19 \mathrm{nmol} \mathrm{cm}^{-3} \mathrm{day}^{-1}$, which indicated that sulfate-reducing microorganisms were reactivated after successive freezethaw cycles.

Total cell numbers were determined by DAPI staining at the end of each frozen and thawed incubation interval (Figure 3B). The initial cell abundance was $7.7 \times 10^{8}$ per ml wet sediment. After the first freeze interval, the cell numbers dropped to $5.6 \times 10^{8}$ per $\mathrm{ml}$. After the second freeze interval, total cell numbers decreased further to $4.7 \times 10^{8}$ per $\mathrm{ml}$ and remained at this level throughout the experiment. The DGGE profiles of PCR-amplified rRNA gene fragments extracted after each freeze and thaw period were similar (Figure 3C). At least, four dominant bands were consistently detected for each freeze and thaw period, suggesting that several major taxa persisted under the freeze-thaw conditions.

\section{Multiple freeze-thaw incubation}

In this experiment, the highest SRR value, $33 \mathrm{nmol} \mathrm{cm}{ }^{-3}$ day $^{-1}$, was determined in the first of the eight freeze-thaw intervals (Figure 4a). In the second and third cycles, the SRR value decreased to 27 and $7 \mathrm{nmol} \mathrm{cm}^{-3}$ day $^{-1}$, respectively, and remained low (3-5 nmol cm${ }^{-3}$ day $^{-1}$ ) in all subsequent thawed phases. In a control incubation that did not experience any freezing, the SRR values were higher and gradually decreased from 40 to $17 \mathrm{nmol} \mathrm{cm}^{-3} \mathrm{day}^{-1}$ over the course of the experiment.

Three VFAs: acetate, lactate and formate were detected during the multiple freeze-thaw incubation. As in the gradual freeze-thaw experiment, no significant trend was apparent for the individual VFA, therefore, summed concentrations are presented in Figure 4b (for three VFAs, the sum analytical error is about $9 \%$ ). A pronounced increase in VFAs was measured over the course of this experiment. Over the first six freeze-thaw cycles, concentrations of VFAs increased from 23 to $202 \mu \mathrm{M}$, and then increased more gradually up to $225 \mu \mathrm{M}$ over the final two cycles. In the control experiments, the concentration of VFAs dropped from 40 to $19 \mu \mathrm{M}$ during the first $30 \mathrm{~h}$ and remained at this level for the duration of the experiment.

\section{Discussion}

Reactivation under freeze-thaw conditions

Continued activity in cyclical freeze-thaw experiments seems to be influenced by the ability of the microbial community to metabolize substrates released by the freeze-thaw treatment (Schimel and Mikan, 2005). Several studies on soil bacteria have demonstrated detrimental effects of freeze-thaw 

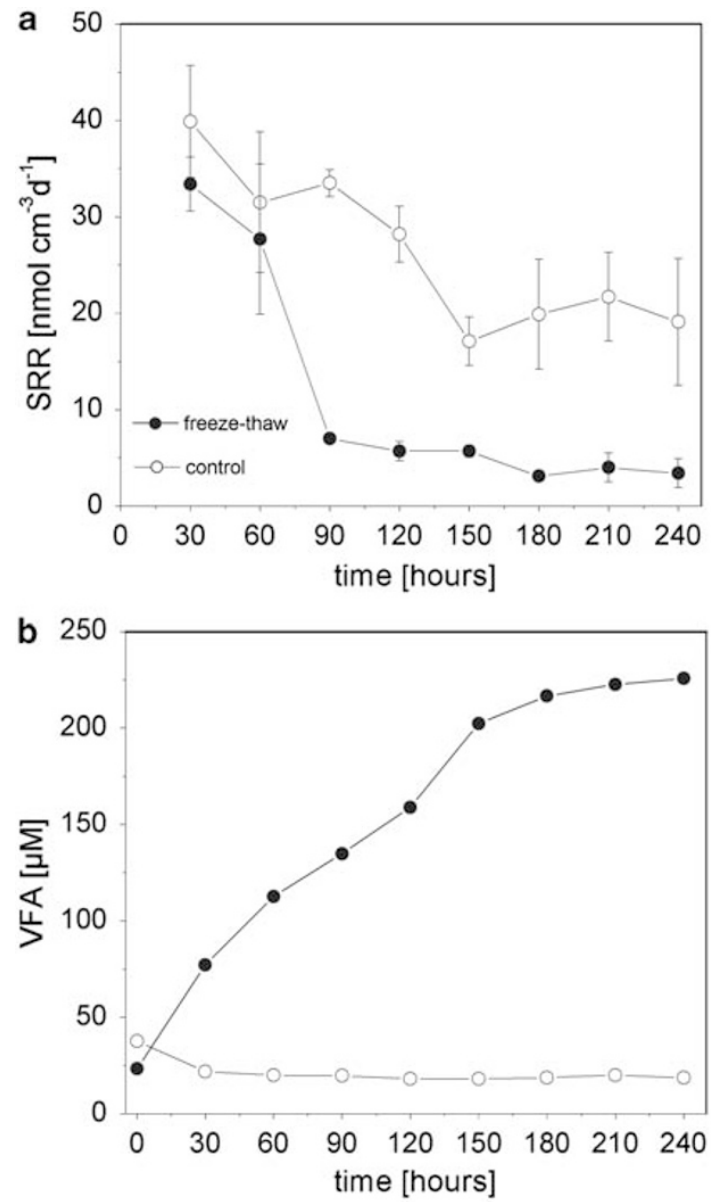

Figure 4 (a) The sulfate reduction rates (SRRs) associated with eight successive 30 -h freeze-thaw cycles. Closed symbols correspond to SRR values measured during 18-h thaw phases (at $10^{\circ} \mathrm{C}$ ) that followed 12 -h frozen phases (at $-20^{\circ} \mathrm{C}$ ). Open symbols correspond to SRR values measured at the same corresponding time points in a control that was constantly maintained at $10^{\circ} \mathrm{C}$. (b) Volatile fatty acids (VFAs) associated with eight successive 30-h freeze-thaw cycles. Closed symbols correspond to concentrations of VFAs measured at the end of each cycle and open symbols correspond to concentrations of VFAs measured at the same times in the control experiment. The analytical error for the summed VFA concentration is about $9 \%$, as described in the text.

event on microbial communities. Such a treatment killed up to $50 \%$ of the microbial population in the first freeze-thaw cycle (DeLuca et al., 1992) and irreversibly reduced the soil DNA content by $33 \%$ (Pesaro et al., 2003). Multiple freeze-thaw cycles decreased culturable populations in soils by four orders of magnitude and reduced morphological diversity (Walker et al., 2006).

Our results demonstrate that freezing temperatures in freeze-thaw regimes temporarily eliminate bacterial activity, but that sulfate-reducing microorganisms can resume active carbon cycling shortly after thawing of the sediment (Figures 2A and 3A). Arctic soil mesocosm studies showed that microbial respiration remained at a high level in multiple diurnal freeze-thaw cycles although the microbial biomass declined (Larsen et al., 2002). By contrast, microbial biomass in alpine soils subjected to moderate freeze-thaw cycles, a temperature change between $3{ }^{\circ} \mathrm{C}$ and $-5{ }^{\circ} \mathrm{C}$, was not affected by these temperature fluctuations (Lipson et al., 2000). In our experiments sulfate-reducing bacteria survived in sediment that was gradually frozen and thawed as SRRs changed with each successive temperature shift between $4{ }^{\circ} \mathrm{C}$ and $-5^{\circ} \mathrm{C}$ (Figure 2a). The most distinct temperature response only occurred in the early stages of the experiment, and it is noteworthy that SRRs did not return to initial levels after repeated freeze-thaw cycles (Figure 2a). Lower SRR values after the first freeze-thaw cycle indicate a decreased capacity for sulfate reduction, possibly due to the loss of cells that could not cope with freeze-thaw stress (Figure 3B). Psychrophilic bacteria generally prevail in permanently cold arctic sediments (Helmke and Weyland, 2004). These organisms possess a broad range of cold-adaptive strategies, such as increased membrane fluidity, low-temperature-adapted enzymes, cold-shock and antifreeze proteins and cryoprotectants (D'Amico et al., 2006), which implies that psychrophiles should be dominant community members in Arctic sediments subjected to freeze-thaw conditions. Similar conclusions were drawn by Walker et al. (2006), who showed that those soil microorganisms that could withstand multiple freeze-thaw cycles treatment possessed cold-adaptation mechanisms. Psychrophiles are understood to be dominant in permanently cold environments, whereas psychrotolerant bacteria can adapt faster to fluctuating temperature (Robador et al., 2009). It is not clear whether this characteristic of psychrotolerant bacteria extends to the temperature fluctuations imposed by the freeze-thaw cycles used here, leaving it uncertain whether psychrophilic or psychrotolerant bacteria were dominant in our incubated sediments.

Multiple freeze-thaw cycles have been shown to decrease microbial respiration by $50-70 \%$ in a soil mesocosm (Larsen et al., 2002). In our multiple freeze-thaw incubations, three successive freeze-thaw cycles resulted in a decrease in SRR value by $80 \%$, however, those sulfate reducers that survived this treatment were able to resume without delay when the sediment was thawed (Figure 4a). Similarly, in the long-term freezethaw incubation sulfate reduction, which was inhibited during frozen phase, resumed when the temperature increased again (Figure 3A). The DAPI counts for the long-term experiment showed that the first freeze-thaw cycle decreased cell number irreversibly by $30 \%$ (Figure 3B). Our observations are in line with those of other studies that showed a decrease in DNA content due to cell lysis under freeze-thaw conditions, whereas microbial respiration appeared unaffected (Pesaro et al., 2003). 
Comparative DGGE analysis of PCR products obtained using universal bacterial 16S rRNA gene primers showed that the microbial community composition in the sediment did not experience major shifts as a result of the freeze-thaw treatments. Our results do not indicate that freeze-thaw treatments selected for or enriched microbial taxa; rather, dominant taxa were maintained throughout the experiment. This finding is in agreement with results of the study by Männistö et al. (2009) in Arctic tundra soil, where only minor changes in microbial community structure were observed after repeated freeze-thaw cycles. Our results are also consistent with lipid biomarker studies of highlatitude soil samples that concluded, on the basis of temperature gradient gel electrophoresis images, that neither microbial community structure nor microbial biomass was affected by freeze-thaw stress (Koponen et al., 2006). It is very likely that the bright bands in the DGGE gel do not necessarily represent sulfate-reducing bacteria but include other bacterial groups as well. In a study on the sulfatereducing bacterial community structure in Svalbard marine sediments, Ravenschlag et al. (2000) determined that sulfate reducers accounted for only $16 \%$ of the total microbial community. Thus, members of the freeze/thaw-resistant community from Ymerbukta sediment, represented by stable intense bands on the DGGE gel, could indicate a broad community of freeze/thaw-resistant bacteria that catalyzed carbon degradation and mineralization in these sediments.

\section{Tolerance of different physiological groups to} freeze-thaw cycles

Low concentrations of VFAs during gradual freezethaw incubations (Figure 2b) suggest that the coupling between fermentation and sulfate reduction was maintained during this experiment. These incubation conditions, therefore, seemed to recreate the normal situation in arctic sediment, that is, low concentrations of VFAs (for example, Figure 1b and 4b) due to close coupling between fermentation and terminal oxidization processes (Finke and Jørgensen, 2008; Robador et al., 2009).

This pattern was not observed during multiple freeze-thaw cycles in which concentrations of VFAs gradually increased during the experiment (Figure 4b). This suggests that detrimental effects of freeze-thaw cycles may have been greater for sulfate reducers than for fermentative microorganisms. These effects suggest major changes in the pathways of carbon processing under repeated freeze-thaw cycles. The long-term fate of VFAs that accumulated after freezing requires further exploration.

Microbial activity in the frozen state

Various studies have reported that microorganisms are capable of growth below the freezing point of water, down to temperatures of $-20^{\circ} \mathrm{C}$ (Gilichinsky et al., 1993; Rivkina et al., 2000; Junge et al., 2004). We find no clear evidence that sulfate reduction remained active at $-20^{\circ} \mathrm{C}$. In addition, the fact that sulfate reduction was only detected in the first freeze cycle of the gradual freeze--thaw experiment at $-5{ }^{\circ} \mathrm{C}$ (Figure 2a) suggests that part of the microbial community, active initially in the first freeze period, was damaged in the subsequent freeze-thaw cycle. Even the fraction of the microbial community that was not damaged during freeze-thaw event was not active when the sediment was frozen, probably because of changes in cell structure at low temperature, for example, membrane lipids stiffen and this decreases the efficiency of embedded transport proteins (Nedwell and Rutter, 1994; Nedwell, 1999; Ponder et al., 2005).

At the Antarctic sites, studied by Mountfort et al. (2003), it was shown that freezing had a strong impact by uncoupling sulfate reduction from acetate oxidation and shifting the carbon flow towards methanogenesis. Mountfort et al. (2003) suggested that freezing provides a physical barrier preventing access of the microbes to sulfate or by reducing the affinity of sulfate reducers for their substrate. Our experiments demonstrate that microbial carbon turnover through bacterial sulfate reduction was not sustained over repeated freeze-thaw cycles in frozen intervals.

\section{Conclusions}

Moderate freeze-thaw conditions have little effect on microbially mediated organic carbon degradation in these intertidal Arctic sediments. It is apparent that the in situ microbial communities can largely withstand drastic temperature fluctuations and are reactivated without delay. Substantial re-growth of microbial populations to resume carbon mineralization is not required. Although this study considered natural communities from intertidal sediments, the results are relevant for considering other coastal marine environments that are subject to temperature fluctuations. Climate warming studies predict an increase in the amplitude of temperature fluctuations in the Arctic regions (Moritz et al., 2002). Many Arctic coastlines are currently in transition as rising sea level inundates and thaws coastal permafrost (for example, Rachold et al., 2000). Thawing coastal permafrost is a significant component of the changing Arctic carbon cycle (Semiletov et al., 2007). At present, mineralization rates of organic matter in thawing permafrost are not well quantified but are likely critically dependent on the reactivation and recovery of bacteria.

\section{Conflict of interest}

The authors declare no conflict of interest. 


\section{Acknowledgements}

We thank N Riedinger for fruitful discussions, and Captain S Henningsen and first mate J Mortensen of MS FARM, as well as the scientific party 2007 and 2008 for the successful expeditions. We also thank the Koldewey Station for support in Ny Alesund, Svalbard (project KOP56; RIS ID 3298). This study is funded by the Deutsche Forschungsgemeinschaft (DFG) Schwerpunktprogramm 'The impact of climate variability on aquatic ecosystems (AQUASHIFT)' BR 2174/1-1 and BR 2174/1-2 and Max Planck Society.

\section{References}

Albert DB, Martens CS. (1997). Determination of lowmolecular-weight organic acid concentrations in seawater and pore-water samples via HPLC. Mar Chem 56: $27-37$.

Arnosti C, Jørgensen BB, Sagemann J, Thamdrup B. (1998). Temperature dependence of microbial degradation of organic matter in marine sediments: polysaccharide hydrolysis, and sulfate reduction. Mar Ecol Prog Ser 165: $58-70$.

D’Amico S, Collins T, Marx JC, Feller G, Gerday C. (2006). Psychrophilic microorganisms: challenges for life. EMBO Rep 7: 385-389.

Deluca TH, Keeney DR, McCarty GW. (1992). Effects of freeze-thaw events on mineralization of soil nitrogen. Biol Fertil Soils 14: 116-120.

Eriksson M, Ka JO, Mohn WW. (2001). Effects of low temperature and freeze-thaw cycles on hydrocarbon biodegradation in Arctic tundra soil. Appl Environ Microbiol 67: 5107-5112.

Finke N. (2003). The role of volatile fatty acids and hydrogen in the degradation of organic matter in marine sediments, $\mathrm{PhD}$ Thesis, Department of Geology, University of Bremen, Bremen.

Finke N, Jørgensen BB. (2008). Response of fermentation and sulfate reduction to experimental temperature changes in temperate and Arctic marine sediments. ISME J 2: 815-829.

Gilichinsky DE, Soina VS, Petrova MA. (1993). Cryoprotective properties of water in the earth cryolithosphere and its role in exobiology. Orig Life Evol Biosph 23: 65-75.

Grogan P, Michelsen A, Ambus P, Jonasson S. (2004). Freeze-thaw regime effects on carbon and nitrogen dynamics in subarctic heath tundra mesocosms. Soil Biol Biochem 36: 641-654.

Helmke E, Weyland H. (2004). Psychrophilic versus psychrotolerant bacteria. Occurrence and significance in polar and temperate marine habitats. Cell Mol Biol 50: $553-561$.

Jakobsson M, Grantz A, Kristoffersen Y, Macnab R. (2002). Physiographic provinces of the Arctic Ocean seafloor. Geol Soc Am Bull 115: 1443-1455.

Jørgensen BB. (1978). A comparison of methods for the quantification of bacterial sulfate reduction in coastal marine sediments. I. Measurement with radiotracer techniques. Geomicrobiol J 1: 11-27.

Junge K, Eicken H, Deming JW. (2004). Bacterial activity at -2 to $-20^{\circ} \mathrm{C}$ in Arctic wintertime sea ice. Appl Environ Microbiol 70: 550-557.

Kallmeyer J, Ferdelman TG, Weber A, Fossing $\mathrm{H}$, Jørgensen BB. (2004). A cold chromium distillation procedure for radiolabeled sulfide applied to sulfate reduction measurements. Limnol Oceanogr Methods 2: 171-180.

Koponen H, Jaakkola T, Keinänen-Toivola MM, Kaipainen S, Tuomainen J, Servomaa K. (2006). Microbial communities, biomass, and activities in soils as affected by freeze thaw cycles. Soil Biol Biochem 38: 1861-1871.

Larsen KS, Jonasson S, Michelsen A. (2002). Repeated freezethaw cycles and their effects on biological processes in two arctic ecosystem types. Appl Soil Ecol 21: 187-195.

Lipson AD, Schmidt KS, Monson KL. (2000). Carbon availability and temperature control the post-snowmelt decline in alpine soil microbial biomass. Soil Biol Biochem 32: 441-448.

Männistö M, Tiirola M, Häggblom MM. (2009). Effect of freeze-thaw cycles on bacterial communities of Arctic tundra soil. Microb Ecol 58: 621-631.

Moritz ER, Bitz MC, Steig JE. (2002). Dynamics of Recent Climate Change in the Arctic. Science 297: 1497-1502.

Mountfort DO, Kaspar HF, Asher RA, Sutherland D. (2003). Influences of pond geochemistry, temperature, and freeze-thaw on terminal anaerobic processes occurring in sediments of six ponds of the McMurdo Ice Shelf, near Bratina Island, Antarctica. Appl Environ Microbiol 69: 583-592.

Muyzer G, Brinkhoff T, Nübel U, Santegoedes C, Schäfer H, Wawer C. (1997). Denaturing gradient gel electrophoresis (DGGE) in microbial ecology. In: Akkermans ADL, van Elsas JD, FJ de Bruijn (eds). Molecular Microbial Ecology Manual vol. 3.4.4. Kluwer: Dordrecht, The Netherlands, pp 1-27.

Nedwell DB. (1999). Effect of low temperature on microbial growth: lowered affinity for substrates limits growth at low temperature. FEMS Microb Ecol 30: 101-111.

Nedwell DB, Rutter M. (1994). Influence of temperature on growth rate and competition between two psychrotolerant Antarctic bacteria: Low temperature diminishes affinity for substrate uptake. Appl Environ Microbiol 60: $1984-1992$.

Nordli Ø. (2005). Temperature variations at Svalbard during the last century. Nordicspace 13: 6-7.

Pernthaler A, Pernthaler J, Amann R. (2002). Fluorescence in situ hybridization and catalyzed reporter deposition for the identification of marine bacteria. Appl Environ Microbiol 68: 3094-3310.

Nübel U, Garcia-Pichel F, Kühl M, Muyzer G. (1999). Spatial scale and the diversity of benthic cyanobacteria and diatoms in a salina. Hydrobiologia 401: 199-206.

Pesaro MF, Widmer F, Nicollier G, Zeyer J. (2003). Effects of freeze-thaw stress during soil storage on microbial communities and methidathion degradation. Soil Biol Biochem 35: 1049-1061.

Ponder MA, Gilmour SJ, Bergholz PW, Mindock CA, Hollingsworth R, Thomashow MF, Tiedje JM. (2005). Characterization of potential stress responses in ancient Siberian permafrost psychroactive bacteria. FEMS Microbiol Ecol 53: 103-115.

Rachold V, Grigoriev MN, Are FE, Solomon S, Reimnitz E, Kassens H, Antonow M. (2000). Coastal erosion vs riverine sediment discharge in the Arctic shelf seas. Int J Earth Sci 89: 450-460.

Ravenschlag K, Sahm K, Knoblauch C, Jørgensen BB, Amann R. (2000). Community structure, cellular rRNA content and activity of sulfate reducing bacteria in 
marine Arctic sediments. Appl Environ Microbiol 66: 3590-3600.

Rivkina EM, Friedmann EI, McKay CP, Gilichinsky D. (2000). Metabolic activity of permafrost bacteria below the freezing point. Appl Environ Microbiol 66: 3230-3233.

Robador A, Brüchert V, Jørgensen BB. (2009). The impact of temperature change on the activity and community composition of sulfate-reducing bacteria in arctic versus temperate marine sediments. Environ Microbiol 11: 1692-1703.

Sagemann J, Jørgensen BB, Greef O. (1998). Temperature dependence and rates of sulfate reduction in cold sediments of Svalbard, Arctic Ocean. Geomicrobiol J 15: 85-100.

Schimel JP, Clein SJ. (1996). Microbial response to freezethaw cycles in tundra and taiga soils. Soil Biol Biochem 28: 1061-1066.

Schimel JP, Mikan C. (2005). Changing microbial substrate use in Arctic tundra soils through a freeze-thaw cycle. Soil Biol Biochem 37: 1411-1418.

Schuur EAG, Vogel JG, Crummer KG, Lee H, Sickman JO, Osterkamp TE. (2009). The effect of permafrost thaw on old carbon release and net carbon exchange from tundra. Nature 459: 556-559.

Semiletov IP, Pipko II, Repina I, Shakhova NE. (2007). Carbonate chemistry dynamics and carbon dioxide fluxes across the atmosphere-ice-water interfaces in the Arctic Ocean: Pacific sector of the Arctic. J Mar Sys 66: $204-226$.

Sharma S, Szele Z, Schilling R, Munch JC, Schloter M. (2006). Influence of freeze-thaw stress on the structure and function of microbial communities and denitrifying populations in soil. Appl Environ Microbiol 72: 2148-2154.

Yergeau E, Kowalchuk AG. (2008). Responses of Antarctic soil microbial communities and associated functions to temperature and freeze-thaw cycle frequency. Environ Microbiol 10: 2223-2235.

Walker VK, Palmer GP, Voordouw G. (2006). Freeze-thaw tolerance and clues to the winter survival of a soil community. Appl Environ Microbiol 72: 1784-1792.

Widdel F, Hansen TA. (1991). The dissimilatory sulphate and sulphur-reducing bacteria. In: The Prokaryotes Vol II, 2nd edn. Springer: New York, pp 583-624. 